\title{
Economia como Ciência Teórica e suas Relações com as Ciências Econômicas Históricas e Práticas - Parte $3^{*}$
}

\author{
Carl Menger ${ }^{* *}$
}

\begin{abstract}
Resumo: Neste texto Menger continua sua crítica às teses metodológicas da Escola Histórica Alemã. Para Menger, toda abordagem teórica exata seria parcial, mesmo nas ciêncais físicas, o que torna impossível a pretensão holística dos alemães. Sob esse ponto de vista rejeita-se tanto a crítica alemã à generalidade do pressuposto de autointeresse quanto a acusação de atomismo lançada a teoria econômica tradicional.
\end{abstract}

Palavras-Chave: batalha dos métodos, auto-interesse, atomismo

\section{Economic as a Theoretical Science and Its Relationship to the Historical and Practical Economic Sciences - Part 3}

\begin{abstract}
In this text, Menger continues his critique of the methodological theses of the German Historical School. For Menger, any exact theoretical approach will be necesarily partial, even in the physical sciences, making it impossible the holistic claim of the Germans. From this point of view the author rejects both the German criticism of the generality of the assumption of self-interest and the imputation of atomism launched against traditional economic theory.
\end{abstract}

Keywords: methodenstreit, self-interest, atomism.

Classificação JEL: B13, B41

\footnotetext{
"O presente artigo é a versão integral dos capítulos 6, 7, e 8 do Livro I da obra Untersuchungen über die Methode der Sozialwissenschaften und der politischen Ökonomie insbesondere [Investigações sobre o Método das Ciências Sociais com especial referência à Economia Política], publicado pela primeira vez em alemão no ano de 1883. Nas duas edições anteriores de MISES: Revista Interdisciplinar de Filosofia, Direito e Economia foram publicados os demais capítulos do Livro I dessa obra de Carl Menger. A presente tradução foi feita a partir da seguinte versão em inglês: MENGER, Carl. Book One: Economics as a Theoretical Science and Its Relationship to the Historical and Practical Economic Sciences. In: Investigations into the Method of Social Sciences with Special Reference to Economics. Ed. Louis Schneider; Intr. Lawrence H. White; Trad. Francis J. Nock. New York: New York University Press, 1985. p. 33-94. A presente tradução para o português foi cotejada pelo tradutor com a versão em espanhol e pelos editores com o original em alemão, publicados, respectivamente, nas seguintes edições: MENGER, Carl. El método de las ciencias sociales. Trad. Juan Marcos de la Fuente, Madrid Unión Editorial, 2006; MENGER, Carl. Untersuchungen über die Methode der Sozialwissenschaften und der politischen Ökonomie insbesondere. Leipzig: Verlag von Dunker \& Humblot, 1883.

Traduzido do inglês para o português por Davi J. Dias.

** Carl Menger nasceu em 23 de fevereiro de 1840 na cidade de Nowy Sącz, atualmente na Polônia e na época parte do território do Império Austro-Húngaro. Estudou Direito nas universidades de Viena e de Praga, e recebeu o título de Doutor em Direito na Universidade Jaguelônica, em Cracóvia. Trabalhou como jornalista e analista econômico para o Lemberger Zeitung, em Lwów na Ucrânia, e para o Wiener Zeitung, em Viena. Lecionou Economia Política e Finanças na Faculdade de Direito da Universidade de Viena. Foi tutor de Economia Política e de Estatísticas do arquiduque Rudolf von Habsburg (1858-1889) de 1876 a 1878. Assumiu a cátedra de Economia Política da Universidade de Viena em 1878 e foi nomeado em 1900 para o conselho imperial de Franz Joseph von Habsburg (1830-1916). É considerado o fundador da Escola Austríaca de Economia, sendo autor de diversos artigos acadêmicos e de vários livros dentre os quais se destaca Princípios de Economia Política (Abril Cultural, 1983). Faleceu no dia 26 de fevereiro de 1921 em Viena.
} 


\section{VI - A Teoria de que se Deve Tratar os Fenômenos Econômicos Apenas em Conexão com o Desenvolvimento Social e Político dos Povos}

Em estreita relação com os erros expostos nos capítulos anteriores ${ }^{1}$ - a saber: a confusão entre compreensão histórica e compreensão teórica dos fenômenos sociais, por um lado, e a concepção unilateral do problema teórico das ciências sociais como problema exclusivamente realista, por outro lado - existe uma doutrina que, mais do que nenhuma outra, se impôs na economia alemã recente, e que não apenas prevalece no pensamento de quase todos os principais economistas contemporâneos da Escola Histórica, mas também, como eles próprios admitem, determina o caráter e a orientação da investigação.

Refiro-me à opinião dos que sustentam que "os fenômenos econômicos só podem ser compreendidos em íntima conexão com o desenvolvimento do conjunto, social e político, dos povos" ${ }^{\prime 2}$, e que estigmatizam:

A autonomização do elemento econômico e sua separação do complexo conjunto formado pela vida do povo e do Estado, sendo isso anti-histórico e desprovido de efeito em relação à vida e, por essa razão, causa de resultados incorretos, uma vez que é preciso reproduzir, por meio da ciência, de acordo com a verdade plena e integral, a realidade inteira da vida ${ }^{3}$.

\footnotetext{
${ }^{1}$ MENGER, Carl. Economia como Ciência Teórica e suas Relações com as Ciências Econômicas Históricas e Práticas - Parte 1. Trad. Davi J. Dias. MISES: Revista Interdisciplinar de Filosofia, Direito e Economia, Volume I, Número 2 (Julho-Dezembro 2013): 375-86; Idem. Economia como Ciência Teórica e suas Relações com as Ciências Econômicas Históricas e Práticas - Parte 2. Trad. Davi J. Dias. MISES: Revista Interdisciplinar de Filosofia, Direito e Economia, Volume II, Número 1 (Janeiro-Junho 2014): 55-67. [N. do E.]
}

2 DIETZEL, Carl. Die Volkswirthschaft und ihr Verhältniss zu Gesellschaft und Staat. Frankfurt: J. D. Sauerländer's Verlag, 1864. p. 52.

${ }^{3}$ KNIES, Karl. Die politische Oekonomie vom Standpunkte der geschichlichen Methode. Braunschweig: C. S. Schwetschke und sohn, 1853. p. 29, 109ss.
Sabe-se que esta concepção ${ }^{4}$ não é nova no âmbito da investigação histórica. Os fenômenos concretos da vida dos povos são fruto de numerosos fatores concorrentes, e não há nenhum que não demonstre a influência de todos os fatores determinantes da forma dos fenômenos. $\mathrm{O}$ historiador que quisesse explicar e fazer-nos compreender um fenômeno complexo ou um grupo de fenômenos valendo-se apenas de uma tendência da atividade humana, ou exclusivamente de um único fator da configuração histórica; ou um historiador que, por exemplo, pretendesse explicar a política exterior baseando-se tão somente no caráter e nos desejos dos diplomatas mais influentes, ou o desenvolvimento da arte de uma época mediante a personalidade dos seus artistas mais notáveis, ou as vitórias militares apenas pelo talento dos generais, em vez de levar em conta todas as condições políticas, culturais e econômicas, na medida em que estas influenciaram os fatos

\footnotetext{
${ }^{4}$ A pretensão de Gustav von Schmoller (1838-1917) de que a Ciência Econômica deve investigar também as "causas psicológicas e morais [...], sistematicamente, em suas relações com a Economia", juntamente com as causas "técnico-naturais", não passa de uma formulação pouco feliz da mesma ideia fundamental (Ver: SCHMOLLER, Gustav von. Über einige Grundfragen des Rechts und der Volkdwirthschaft. Jena: Drack und Verlag von Friedrich Mauke, 1875. p. 42ss.). Com efeito, entre ambos os grupos de causas, não existe, a rigor, diferença nenhuma. Por exemplo, as necessidades humanas e a conseguinte tendência de satisfazêlas - sem dúvida, os fatores mais importantes das ciências humanas - são causas tanto naturais, como psicológicas dos fenômenos econômicos. Schmoller, não obstante, como se pode deduzir do conjunto de sua exposição, considera-as como causas somente naturais, ou mesmo como causas "técnico-naturais", contrapondo-as às causas psicológicas e morais da economia. Na realidade, a contraposição só existe entre a tendência especificamente econômica (orientada para a satisfação da necessidade de bens) e as demais tendências, não econômicas, de cujo concurso global surge a vida real, uma vida social cuja realidade não deveria ser apresentada apenas como resultado da tendência econômica. Esta observação tão simples não é aprofundada, mas obscurecida pelas categorias de Schmoller.
} 
históricos, não poderia evitar ser taxado de profundamente parcial por todos os seus colegas.

O que foi dito aplica-se igualmente aos fatos históricos do direito e da economia. Quando Friedrich Carl von Savigny (17791861) logrou dar aos juristas alemães uma consciência, mais clara do que a de então, da importância dos estudos jurídicos históricos para compreender o direito, em nenhum momento duvidou de que o direito - "cuja conexão orgânica com a essência e o caráter do povo"s 1 he era evidente - tivesse uma existência autônoma; sua existência, como a da linguagem, consiste antes na própria vida do homem, considerada em uma perspectiva particular6. Interpretar historicamente o direito, em suas expressões concretas, por meio de uma determinada tendência, ou, em geral, de um determinado ponto de vista unilateral, ignorando, assim, a influência de todos os demais fatores culturais e de todos os outros acontecimentos históricos, era-lhe tão impensável quanto, por exemplo, a um historiador da economia pretender explicar o desenvolvimento histórico recorrendo, exclusivamente, a uma única tendência, digamos, ao auto-interesse dos povos ou dos indivíduos. Direito e economia, em sua forma concreta, são partes da vida global de um povo e, portanto, só podem ser compreendidos, historicamente, em conexão com o conjunto de sua história. Não há dúvida de que os historiadores devem reconduzir os fatos econômicos ao conjunto de fatores físicos e culturais que contribuíram para lhes dar forma; não resta nenhuma dúvida razoável de que a compreensão histórica da economia e de seus fenômenos só pode ser obtida "relacionando-os com o desenvolvimento político e social dos povos", ao passo que desvincular o elemento econômico do conjunto da vida social e política, no sentido referido acima,

\footnotetext{
${ }^{5}$ SAVIGNY, Carl von. Vom Beruf unserer Zeit zur Gesetzgebung und Rechtswissenschaft. Heidelberg: Mohr und Zimmer, 1814. p. 11.

${ }^{6}$ Idem. Ibidem., p. 30.
}

seria anti-histórico e inadequado à vida real. Sobre tudo isso, repetimos, não cabe a menor dúvida, e, de fato, no que diz respeito à compreensão histórica dos fenômenos econômicos, os historiadores nunca o puseram em questão (exceto alguns filósofos da história que pretenderam reconstruir os acontecimentos históricos a partir de uma óptica unilateral).

Ora, só o fracasso em reconhecer a natureza das ciências teóricas e do autêntico caráter da sua compreensão teórica dos fenômenos - em particular o da compreensão dos fenômenos econômicos que a economia teórica visa a nos oferecer - só esse fracasso pôde induzir alguns economistas a aplicar simplesmente, ou seja, de modo totalmente mecânico, os critérios da história e da compreensão histórica à teoria e à compreensão teórica dos fenômenos econômicos.

Mas aqui nos ocuparemos de tal postulado em relação, primeiro, à orientação exata, e, a seguir, em relação à orientação realista da investigação teórica no campo da economia.

Entre as teorias exatas, não existe nenhuma que nos possa dar um conhecimento teórico universal do mundo fenomênico, ou de uma parte qualquer dele, nem sequer de um fenômeno particular complexo considerado em sua totalidade; tal conhecimento só o podemos obter pelo conjunto das ciências exatas, já que cada uma delas nos proporciona apenas a compreensão de um aspecto particular do mundo real.

Quem deseja compreender os fenômenos da natureza, tal como no-los mostra a experiência, ou antes um grupo de fenômenos, ou até mesmo um único fenômeno natural, de maneira exata, ou melhor, como exemplificação da rigorosa regularidade vigente em todos os fatos naturais, não deverá recorrer apenas às leis da química, da mecânica ou da física, etc., mas a todas as ciências exatas ou à maioria delas, pois somente assim poderá obter um conhecimento exato também daquelas fases e daqueles aspectos dos fenômenos reais que, a partir do ponto de vista de uma única 
ciência exata, poderiam talvez parecer irregularidades, isto é, exceções à rigorosa regularidade do mundo dos fenômenos. Nenhuma ciência exata, por si só, nos pode oferecer um conhecimento teórico universal, nem sequer de uma parte mínima do mundo real, pois, como já explicamos, só é capaz de nos apresentar uma faceta particular desta regularidade.

Deveremos, por isso, chamar a química, a física, a mecânica, etc., de ciências unilaterais? Acaso poderá ocorrer a um cientista natural a ideia de ampliar os limites dessas ciências até ao ponto de fazer de cada uma delas uma teoria dos fenômenos naturais em geral? Ou quem sabe uma pessoa medianamente versada em problemas teóricos poderá desdenhar, como "abstratas", dessas disciplinas, pelo fato mesmo de que cada uma delas não pode explicar nem sequer um único fenômeno em sua plena realidade empírica?

É um princípio fundamental de toda e qualquer metodologia que as diferentes ciênciasexatas, consideradasindividualmente, podem dar-nos apenas o conhecimento de um aspecto particular do mundo real. E quem, em vez de aspirar à compreensão universal dos fenômenos concretos por meio do conjunto dessas ciências, pretende alcançar este resultado ampliando cada uma delas até erigi-la em teoria universal de determinados setores fenomênicos, em sua plena realidade empírica, nega os princípios mais elementares da ciência, a ponto mesmo de fazer duvidar de sua qualificação para participar da discussão de um problema tão difícil como este ${ }^{7}$.

7 O erro da questão é tão óbvio, tão antigo, que já foi claramente percebido por um autor como JeanBaptiste Say (1767-1832), que, aliás, não é de todo digno de crédito em questões metodológicas. Escreve o economista francês:

Les phénomènes de la politique eux-mêmes n'arrivent point sans causes, et dans ce vaste champ d'observations, un concours de circonstances pareilles amène aussi des résultats analogues. L'économie politique montre l'influence de plusieurs de ces causes; mais comme il en existe beaucoup d'autres [...] toutes les sciences n'en feraient qu'une, si l'on ne pouvait cultiver une branche de nos connaissances sans cultiver toutes celles qui s'y rattachent; mais alors, quel esprit pourrait embrasser
Mas o que mais desejam os defensores de tal doutrina, senão transformar a economia teórica, que como ciência exata é somente uma teoria do aspecto econômico da vida de uma nação (e só pode ser isso!), no fantasma de uma teoria universal dos fenômenos sociais?

Se a humanidade alcançar um conhecimento exato universal dos fenômenos sociais e, particularmente, dos econômicos (em sua plena realidade empírica), será apenas por meio de uma maioria de ciências exatas, cujo conjunto permita-nos compreender os fenômenos sociais em sua totalidade. Somente assim poderemos compreender, de maneira exata, as influências e os efeitos não econômicos sobre os fenômenos reais que definimos como econômicos; não por intermédio da teoria econômica pura, mas de outras ciências sociais em cujo âmbito se inscrevem essas influências, e isso de modo exato, ou seja, não como exceções à regularidade dos fenômenos econômicos, mas como exemplificações de leis sociais (porém, é óbvio, não como leis econômicas). Os economistas poderão estimular com os seus melhores desejos e com todas as suas forças a construção dessas ciências. Antes disso, no entanto, correspondendo à tarefa científica que nos compete, devemos nos esforçar para purificar a economia exata de seus erros e remediar suas carências, a fim de compreender, cada vez com maior exatidão, o aspecto econômico dos fenômenos sociais. Tal

une telle immensité! On doit donc, je crois, circonscrire les connaissances qui sont en particulier le domaine de l'économie politique (SAY, Jean-Baptiste. Cours complet d'Économie Politique. Paris: Guillaumin, 1852. 2v. Vol. I, p. 5ss).

[N. do T.: Carl Menger cita Jean-Baptiste Say no original em francês. Apresentamos, a seguir, a tradução do trecho: "Os fenômenos da política não ocorrem sem causas e, nesse vasto campo de observações, um concurso de circunstâncias similares conduz também a resultados análogos. A economia política mostra a influência de muitas dessas causas; mas, como existem muitas outras [...], todas as ciências constituiriam uma só, se não fosse possível cultivar um ramo do nosso conhecimento sem cultivar todos os que se ligam a ele; mas que inteligência poderia abarcar tal imensidade! Deve-se, pois, assim penso, delimitar o conjunto de conhecimentos que são, de modo particular, o domínio da economia política"]. 
é a nossa ocupação científica mais imediata e urgente, dada a lamentável situação em que a teoria econômica se encontra atualmente.

Mas aqueles que veem nisto unilateralidade e parcialidade, e querem volatizar a economia pura em uma teoria dos fenômenos sociais em sua totalidade, confundem, uma vez mais, o ponto de vista histórico com o conhecimento teórico, e não percebem que a história tem a função de nos dar a conhecer todos os aspectos de certos fenômenos, enquanto as teorias exatas visam a ensinar-nos certos aspectos de todos os fenômenos. Uma ciência que satisfaça plenamente sua própria função não pode ser chamada de unilateral.

Logo, a ideia de que se devem considerar os fenômenos econômicos em estreita conexão com o desenvolvimento social e político dos povos é um absurdo metodológico, ao menos como postulado da orientação exata da investigação teórica no campo econômico.

Mas tampouco na orientação realista da investigação teórica pode-se falar de uma conexão inseparável da economia humana com o desenvolvimento geral da vida social e política dos povos. Os "tipos reais" e as "leis empíricas" também não são, absolutamente, fruto de uma consideração dos fenômenos sociais em todos os seus aspectos; são, antes, resultado de uma abstração de algumas de suas facetas, por mais realista que possa ser a investigação teórica.

Mesmo na concepção mais realista dos problemas teóricos, as leis dos fenômenos significam, sempre, que umas formas fenomênicas costumam se seguir a outras formas ou coexistem com elas. Portanto, no próprio conceito de "leis", e também no de leis empíricas, está implícita, em mais de um sentido, uma evidente abstração da plena realidade empírica. Semelhante abstração aparece já no fato de que, seja qual for a "lei" que concebemos, não se trata (como na história!) da sucessão ou coexistência de fenômenos concretos, mas da sucessão ou coexistência de formas fenomênicas. Daí que seja inevitável certo grau de abstração de algumas características dos fenômenos em sua plena realidade empírica. Ademais, a abstração está também no fato de que as "leis", ao constatar a sucessão ou a coexistência de determinadas formas fenomênicas - sem incorporar em sua formulação, como está claro, qualquer outra forma fenomênica imaginável - devem necessariamente isolar estas últimas, isto é, abstraí-las dos demais fenômenos. No conceito de "leis dos fenômenos", inclui-se, necessariamente, certa abstração da plena realidade dos fenômenos concretos, abstração que não é casual, não é uma deficiência de determinada orientação teórica - a qual se deve evitar - mas algo tão inseparável das "leis dos fenômenos" de qualquer tipo, que a tentativa de evitá-la de todo eliminaria, realmente, a possibilidade de elaborar as leis fenomênicas'.

Portanto, mesmo a orientação mais realista imaginável da investigação teórica deve operar por meio de abstrações; e a aspiração por tipos e relações típicas de fenômenos reais que se refiram, sempre, à "plena realidade empírica" destes últimos, simplesmente contradiz a natureza da investigação teórica, tal como esta se nos mostra na realidade.

Mas, se prescindirmos da abstração que forçosamente deriva da natureza da investigação teórica, é difícil compreender de quais reformas a orientação realista ainda necessita, para levar em conta a plena realidade empírica. Se, como exige essa orientação, as leis econômicas se estabelecem de modo puramente empírico, ou seja, mediante a observação da sucessão real e da coexistência dos fenômenos, é que, já nesse procedimento em si, temos uma completa consideração

\footnotetext{
8 Este postulado, tão contrário à natureza da investigação teórica, foi de fato formulado por alguns dos economistas alemães mais radicais da Escola Histórica, os quais, em seu total desconhecimento da natureza da investigação teórica, davam a entender que consideravam sempre a totalidade da vida dos povos (e por que não de todo o universo, já que aqui, também, há uma abstração?), ao elaborar as leis (realistas!) da economia. Na realidade, porém, somente conseguiram extraviar completamente a investigação teórica para cair no terreno da historiografia.
} 
da realidade empírica, prescindindo das circunstâncias mencionadas acima. Os preços reais dos bens, as rendas reais da terra, os rendimentos reais do capital, etc., são sempre resultado não apenas de tendências especificamente econômicas, mas também éticas; quando constatamos empiricamente as regularidades na sequência e coexistência desses fenômenos, consideramos também, na medida do concebível, a influência do direito, dos costumes, etc., sobre as relações econômicas típicas, sem que seja possível precisar até que ponto deve-se considerar esta influência, já que, como salta aos olhos, as leis empíricas são válidas apenas nas condições espaço-temporais em que foram elaboradas.

A tendência da orientação realista de considerar os fatores não econômicos da economia é, pois, supérflua, uma vez que está implícita em sua própria natureza; por isso, não é necessário nenhum método especial e, muito menos, uma escola específica. Ao contrário, precisa-se de mentes singularmente dotadas, capazes de formular "leis empíricas" dos fenômenos econômicos, das quais fossem eliminados os fatores não econômicos - tal como o imaginam os nossos economistas historiadores.

Este postulado envolve um equívoco curioso, relativo tanto à orientação exata, quanto à orientação empírica da investigação teórica.

$\mathrm{Na}$ realidade, a exigência de que "os fenômenos econômicos devem ser tratados em conexão com todo o desenvolvimento social $e$ estatal dos povos" tem suas raízes na obscura aspiração de transportar para a ciência teórica da economia os pontos de vista próprios da investigação histórica, aspiração que contradiz a natureza desta orientação cognoscitiva. Também aqui os nossos economistas historiadores demonstram sua escassa experiência em temas metodológicos, ao tentar obter de uma orientação investigativa mais do que ela por natureza pode dar, e, com o temor de parecerem unilaterais, passam do seu próprio campo de estudo - a economia política - para o da historiografia. Esse é um tipo de pluralismo em relação ao qual a ciência alemã procederia melhor se o evitasse.

\section{VII - O Dogma do Auto-interesse na ECONOMIa TEÓRICA E SUA RElaÇÃo COM os Problemas Teóricos desta Ciência}

“O egoísmo privado - isto é, o autointeresse- desempenha, na teoria econômica, um papel tão importante, e está tão direta e profundamente ligado ao método de elaboração das leis econômicas; exerceu uma influência tão determinante na posição de nossa ciência", que não podemos deixar de lado a sua relação com os problemas cognoscitivos da economia, tanto mais quanto, segundo nosso parecer, "o método histórico na economia política mantém uma relação muito especial com o dogma do autointeresse imutável"9.

Por "dogma do auto-interesse" entendem alguns economistas o princípio segundo o qual a atividade econômica orientada para buscar o interesse privado individual, não influenciada por medidas governamentais político-econômicas, origina, também, o máximo bem-estar coletivo que determinada comunidade pode alcançar, em sua situação concreta de tempo e lugar. Todavia, não pretendemos aqui tratar dessa opinião, errônea, ao menos, em sua forma geral, já que não mantém relação alguma com os problemas metodológicos de que nos ocuparemos neste capítulo.

O que antes nos interessa aqui é a afirmação bem conhecida de que os homens, em sua atividade econômica, guiam-se exclusivamente pela consideração econômica de seu próprio auto-interesse, proposição que - conforme sustentam os economistas da Escola Histórica Alemã - os representantes das escolas "anti-históricas" colocam, como axioma fundamental, no vértice de seus próprios sistemas de economia política. A sua importância para os problemas teóricos aqui

\footnotetext{
9 KNIES, Karl. Die Politische Oekonomie vom Standpunkte der geschichtlichen Methode. Brunswick: C. A. Schwetschke und Sohn, 1853. p. 147.
} 
tratados será esclarecida, talvez, pelo fato de que a Escola Histórica liga, à validade deste princípio, a possibilidade de leis rigorosas e, portanto, da própria ciência econômica. Por conseguinte, demonstrada a falsidade desse "dogma", rejeita-se a possibilidade de uma ciência das "leis" econômicas; donde ser necessário um método especial para lidar com a nossa ciência: o método histórico.

$\mathrm{O}$ argumento dos nossos historicistas é o seguinte: a vontade do homem guiase por numerosas motivações - algumas, inclusive, contraditórias entre si; por isso, deve-se excluir, a priori, uma rigorosa regularidade nas ações humanas, em geral, e nas econômicas, em particular. Se, e somente se, pensarmos que o homem orienta-se sempre por um mesmo motivo em suas ações econômicas - por exemplo, pelo auto-interesse -, toda e qualquer ação parecerá rigorosamente determinada, ficando excluído o fator do livre-arbítrio. Logo, é somente sob tais pressupostos que se podem conceber as leis econômicas e, com elas, também a própria economia, no sentido de uma ciência exata.

Ora, a experiência ensina-nos que os homens não se guiam exclusivamente por um único motivo, seja nas suas ações em geral, seja no seu comportamento econômico em particular. Juntamente com o auto-interesse, que, quando muito, se poderia considerar a mola real da economia humana, também contam o sentimento comunitário, o amor ao próximo, os costumes, o senso de justiça e muitos outros motivos; logo, é falso o pressuposto de que partem os economistas (anti-históricos) da escola smithiana. E com este pressuposto cai também o fundamento de leis econômicas rigorosas e independentes das condições de tempo e lugar, assim como a possibilidade mesma de semelhante ciência. Toda a orientação de investigação que vimos descrevendo seria, pois, falsa e antiempírica, e somente uma investigação purificada desses pressupostos errôneos poderia obter, no âmbito de nossa ciência, resultados de acordo com os fenômenos reais da economia.
Tal é, mais ou menos, o argumento dos economistas da Escola Histórica Alemã para combater o "dogma do auto-interesse humano"10.

De nossa parte, gostaríamos, acima de tudo, de assinalar uma lacuna que chama a atenção de qualquer pessoa minimamente familiarizada com as investigações em psicologia. Não é apenas a circunstância de que os homens não se guiam exclusivamente pelo auto-interesse que exclui a possibilidade de obter leis rigorosas das ações humanas, em geral, e das econômicas, em particular, e, portanto, a possibilidade de uma teoria rigorosa da economia. Refiro-me ao erro, um fator que, decerto, não se pode considerar separadamente do agir humano mais do que se podem considerar separadamente da economia os costumes, o senso comum, o senso de justiça e o amor ao próximo. Não obstante os homens, em suas ações econômicas, se deixarem levar, sempre e em todo lugar, unicamente pelo auto-interesse, o fato de que se equivoquem quanto ao seu próprio interesse econômico, ou de que desconheçam a situação real da economia, deveria, contudo, excluir a rigorosa regularidade dos fenômenos econômicos. Nossos historicistas são demasiado indulgentes com seus adversários científicos. O pressuposto de uma estrita regularidade dos fenômenos econômicos e, pois, de uma economia teórica no sentido mais amplo do termo, não é somente o dogma do auto-interesse imutável, mas também o dogma da "infalibilidade" e da "onisciência" dos homens em matéria econômica.

Estamos longe de afirmar que, com os dogmas mencionados, se esgote a totalidade dos pressupostos de uma teoria rigorosa dos fenômenos econômicos, no sentido em que a entendem os nossos historicistas. Para quem tem a mais mínima experiência em investigações metodológicas, é evidente que a esses dogmas dever-se-ia adicionar outra série análoga (no campo dos fenômenos econômicos,

${ }^{10}$ Ver: SCHMOLLER. Über einige Grundfragen des Rechts und der Volkdwirthschaft. p. 42. 
o dogma da plena liberdade em relação a toda coação externa, etc.), dogmas que, sem dúvida, deveriam oferecer, aos representantes da Escola Histórica, um campo igualmente fértil e fácil para a crítica inteligente. O que foi dito, porém, deveria bastar para demonstrar, à evidência, o extraordinário absurdo que há séculos vem sendo fomentado pelas mentes mais notáveis das nações, ao se empenharem em formular teorias rigorosas dos fenômenos sociais, assim como o deplorável estado de erros em que se encontraria a humanidade se não lhe tivesse aberto os olhos a Escola Histórica dos economistas alemães.

Considerando uma revolução historicamente tão importante no campo das ciências sociais, pode parecer estranho, de certo modo, o fato de que aqueles erros pelos quais censuramos os cientistas no âmbito econômico estejam igualmente presentes em todos os demais campos da investigação teórica, sobretudo no das ciências naturais. Consequentemente, é também estranho que toda uma série de ciências teóricas se mostrem, a um exame mais atento, errôneas e sem valor, sem que até agora os nossos cientistas naturais não tenham sequer desconfiado disso.

As ciências naturais teóricas mais importantes e fundamentais também sofrem da mesma fraqueza de que os nossos historicistas acusam as teorias precedentes, no campo das ciências sociais; também a química, a física, não menos do que muitas ciências exatas, como a mecânica, a matemática, etc., quando medidas pelos padrões críticos dos nossos historiadores, parecem contrárias à realidade, antiempíricas e, pois, necessitadas da mesma reforma que se propõe para a economia teórica.

A química não nos ensina os "conceitos reais" de determinados grupos de fenômenos concretos; seus elementos e suas combinações são, antes, antiempíricos em sua pureza plena, e não se observam na natureza isenta de qualquer influência da atividade humana; em certa medida, não podem sequer ser obtidos artificialmente. O ouro puro, o hidrogênio puro e o oxigênio puro, assim como suas combinações puras, não são obtidos empiricamente, nem em si mesmos, nem naquela rigorosa medida ideal que as leis químicas pressupõem. A química opera com fatores qualitativa e, em certo sentido, também quantitativamente, não empíricos. Além disso, não considera os corpos em sua totalidade fenomênica; informa-nos sobre sua natureza e suas leis não em relação a todos os aspectos de seu ser, mas apenas em relação a um deles. Na opinião dos nossos historicistas, a química parte do dogma de que os elementos químicos e suas combinações apresentam-se, empiricamente, em toda a sua pureza, são idealmente mensuráveis com toda a precisão, e de que o ouro e o oxigênio apresentamse como fenômenos reais e são exatamente iguais em todo tempo e lugar; ademais, ocupa-se apenas de um aspecto do mundo real e, portanto, relativamente à totalidade do mundo dos fenômenos, suas leis baseiam-se em pressupostos arbitrários e não empíricos.

Obviamente, o mesmo pode-se aplicar à física e, também, à mecânica e à matemática.

A mecânica pura, em suas leis mais importantes, parte do pressuposto arbitrário e não verificável de que os corpos se movem no vácuo; que seu peso e suas trajetórias são exatamente mensuráveis; que seu centro de gravidade pode ser estabelecido com precisão; que as forças que põem os corpos em movimento são exatamente conhecidas e constantes; que não há a atuação de elementos perturbadores; e assim - para usar a linguagem dos nossos historicistas - sucede com milhares de outros dogmas arbitrários e não verificáveis. E esses dogmas, como os da matemática, cujos pressupostos não empíricos não precisamos assinalar particularmente (pensemos no ponto, na linha, na superfície, etc.!), também não abrangem o mundo dos fenômenos reais em sua totalidade, mas tratam somente de um de seus aspectos. Pelo mesmo motivo, são ciências arbitrárias e antiempíricas (em relação à "plena realidade empírica"), lamentáveis erros da inteligência humana.

Até agora ninguém havia se dado conta de todos esses falsos dogmas, até que a Escola 
Histórica dos economistas alemães nos abriu os olhos, em parte com plena consciência, em parte com o instinto do gênio. E o fez sem se aperceber do enorme alcance desta revolução, que marcou época no campo da investigação exata. Não há dúvida de que os nossos historicistas podem ufanar-se dessa conquista!

Falemos, porém, com a seriedade que o tema exige. A orientação exata da investigação teórica no campo dos fenômenos sociais - e somente em relação a estes pode-se falar do dogma do auto-interesse-, como já explicamos anteriormente, tem a missão de "reduzir os fenômenos humanos às manifestações das forças e dos impulsos originários e mais gerais da natureza humana". Tem o objetivo de, "isto posto, investigar a que formas conduz o livre jogo de cada tendência individual da natureza humana, sem ser influenciada por outros fatores (particularmente, pelo erro, pela ignorância da situação e pela coação externa)". Seguindo esta orientação, chegamos a uma série de teorias sociais, cada uma das quais, abstraída da plena realidade empírica, nos permite compreender somente um aspecto dos fenômenos da atividade humana. O conjunto dessas teorias, todavia, nos permite conhecer o mundo moral do mesmo modo que qualquer outra ciência teórica que seja fruto de uma observação análoga da natureza ${ }^{11}$.

Entre as atividades humanas, estão aquelas (as econômicas) que se orientam para a previsão e a provisão de bens materiais (econômicos), e que são, de longe, as mais gerais e mais importantes; analogamente, entre os impulsos humanos, aquele que impele todo indivíduo a lutar por seu próprio bem-estar é, de longe, o mais geral e o mais poderoso. Uma teoria que nos mostrasse a que formas da atividade humana e dos fenômenos humanos conduz aquela atividade orientada a satisfazer as necessidades de bens, mediante o livre jogo desse poderoso fator da economia humana, à margem de toda influência deoutras tendências e considerações (particularmente, do erro e da

\footnotetext{
${ }^{11}$ Vide: MENGER. Economia como Ciência Teórica e suas Relações com as Ciências Econômicas Históricas e Práticas - Parte 2. p. 60.
}

ignorância); uma teoria que, sobretudo, nos dissesse em que medida, a uma certa quantidade destes fatores, se seguiriam determinados efeitos, nos permitiria compreender, não digo os fenômenos humanos em sua totalidade, nem sequer determinada parte deles, mas um dos aspectos mais importantes da vida humana. A "teoria exata da economia" é uma teoria desse tipo, uma teoria que nos ensina a investigar e a compreender, de modo exato, as manifestações do egoísmo humano naquela atividade destinada a satisfazer as necessidades econômicas; isto é, uma teoria que não tem a função de fazer-nos compreender os fenômenos sociais em geral e em sua totalidade, ou, até mesmo, os fenômenos humanos, nem sequer aqueles que normalmente chamamos de "econômicos". Tem, por objetivo único, fazer-nos entender apenas um aspecto particular da vida humana, o aspecto econômico, sem dúvida o mais importante. Por outro lado, não se poderia compreender os demais aspectos da vida humana senão por meio de outras teorias que nos dessem consciência das formações da vida humana à luz das suas demais orientações (por exemplo, à luz do senso comum, do estrito domínio da ideia do direito, etc.).

Os grandes teóricos no campo dos fenômenos éticos partiram, desde o início, desses pressupostos metodológicos nos quais se basearam Platão (427-347 a.C.) e Aristóteles (384-322 a.C.) para construir suas teorias sociais. Neles também se baseou o grande fundador de nossa ciência, Adam Smith (1723-1790), em sua obra sobre A Riqueza das Nações ${ }^{12}$, assim como em sua Teoria dos Sentimentos Morais ${ }^{13}$, em que os referidos

\footnotetext{
${ }^{12}$ Dentre as inúmeras edições em língua portuguesa desta obra, uma das versões de mais fácil acesso ao público brasileiro é a seguinte: SMITH, Adam. A Riqueza das Nações: Investigação sobre sua Natureza e suas Causas. Apres. Wiston Fritsh; Intr. Edwin Cannan, Trad. Luiz João Baraúna. São Paulo: Abril Cultural, 1983. 2v. [N. do E.]

${ }^{13}$ Em língua portuguesa a obra pode ser encontrada na seguinte edição brasileira: SMITH, Adam. Teoria dos Sentimentos Morais. Trad. Lya Luft. São Paulo: Martins Fontes, 1999. [N. do E.]
} 
pressupostos constituem o eixo central de suas investigações, como o auto-interesse o é de sua obra de economia política, historicamente tão importante.

Retomando agora o chamado "dogma" do auto-interesse, que, segundo a opinião dos economistas da Escola Histórica, deveria implicar numa perturbadora contradição em relação à "plena realidade empírica", não precisamos prosseguir com os nossos argumentos para demonstrar que essa concepção se equivoca sobre os autênticos critérios metodológicos que orientaram os grandes fundadores das ciências morais, em sua atividade de pesquisa. Assim como a mecânica pura não nega a existência de espaços repletos de ar, do atrito, etc., e tampouco a matemática pura nega a existência de corpos, linhas e superfícies reais; assim como a química pura não exclui, absolutamente, a influência de fatores físicos (ou a física, a influência de fatores químicos) na formação dos fenômenos reais, ainda que cada uma destas ciências limite-se a considerar um só aspecto do mundo real, deixando de lado todos os demais - do mesmo modo, o economista não crê que, de fato, os homens se guiem unicamente pelo auto-interesse e sejam infalíveis e oniscientes. Não o crê, pelo motivo mesmo de que o seu objeto de estudo são as formas de vida social, a partir do ponto de vista do livre jogo não influenciado por outras considerações, pelo erro ou pela ignorância. $\mathrm{Na}$ concepção dos nossos historicistas, o dogma do egoísmo humano não passa de um equívoco.

Aristóteles e Hugo Grotius (15831645) sabiam perfeitamente que, além do impulso para a socialização ou para a vida comunitária, há outros fatores que contribuem para a formação dos Estados. Sem dúvida, Thomas Hobbes (1588-1679) sabia que o conflito de interesses dos indivíduos não é o único motor das formas sociais, e o mesmo pensava Baruch Espinoza (1632-1677) acerca do impulso de autoconservação. ClaudeAdrien Helvétius (1715-1771), Bernard Mandeville (1670-1733) e Adam Smith sabiam tão bem quanto qualquer economista da Escola Histórica que o auto-interesse não é o único elemento a influenciar os fenômenos da vida humana. Smith chegou a escrever, ele próprio, uma teoria dos sentimentos morais! O que distingue Smith e sua escola dos nossos historicistas é que eles não confundem a história econômica com a teoria, nem seguem unilateralmente a orientação que antes denominamos de empírico-realista, nem tampouco são vítimas do erro de considerar o "dogma" do egoísmo humano como o único impulso efetivo das ações humanas, vistas na perspectiva do livre jogo do auto-interesse não influenciado por outras forças. E não duvido de que também a economia alemã, uma vez que seus representantes tenham-se conscientizado plenamente do equívoco de que estamos tratando, aceitará de novo aquela orientação de investigação, inteiramente legítima e indispensável para compreender os fenômenos econômicos, durante tanto tempo tão negligenciada, e contribuirá para o seu desenvolvimento, na medida em que lhe corresponde. A situação extremamente insatisfatória da pesquisa exata no campo dos fenômenos econômicos intima fortemente, até os próprios economistas alemães, a que se abandone o caminho equivocado por onde se vão isolando e a que empreguem suas forças na grande tarefa da edificação de uma teoria exata da economia nacional - à parte o anseio de estabelecer um conhecimento realista na esfera da economia e, em particular, de interpretar historicamente os fenômenos econômicos.

\section{VIII - A ImputaÇÃo de "Atomismo" NA ECONOMIA TEÓRICA}

Gostaríamos também de mencionar outra opinião, muito difundida, sobretudo entre os economistas alemães, que deriva, em última análise - como aquela considerada anteriormente -, da transposição mecânica de alguns pontos de vista da investigação 
histórica para a ciência econômica teórica, bem como de uma visão unilateral dos problemas desta última - opinião da qual é possível, portanto, tratar aqui. Referimo-nos à acusação de "atomismo" lançada levianamente contra a economia, na literatura econômica alemã mais recente, censura feita, aliás, a todos aqueles que se ocupam das autênticas funções da economia teórica, e que supostamente baseia-se no fato de que os fenômenos econômicos reduzem-se, na teoria, em última instância, às atividades econômicas dos indivíduos, isto é, a seus elementos constitutivos mais simples, sendo por estes explicados.

Esta opinião também deve sua origem, principalmente, à Escola Histórica do Direito, de cujos métodos foi mecanicamente tomada de empréstimo, assim como muitas outras partes da metodologia de nossa Escola Histórica de Economia. Escreve Savigny:

Não existe nenhum ser humano que esteja de todo isolado e afastado; mais propriamente, o que pode ser visto como um indivíduo singular é, quando considerado a partir de outro ponto de vista, parte integrante de uma unidade superior. Logo, todo indivíduo deve, necessariamente, ser considerado como membro de uma família, de um povo, como a continuação e o desenvolvimento dos tempos passados $^{14}$.

Savigny fala também da natureza superior do povo como um todo, em contínuo crescimento e desenvolvimento, de que a época presente representa apenas um elemento, etc.

É fácil perceber certa afinidade entre esta concepção e aquela dos economistas alemães da Escola Histórica, ainda que os resultados a que ambas as partes conduzem, partindo do mesmo pressuposto, sejam essencialmente diferentes.

A Escola Histórica do Direito se serve da ideia mencionada para concluir que o direito é algo que está acima da arbitrariedade do indivíduo; mais ainda, é independente da arbitrariedade das correspondentes gerações de

14 Ver: SAVIGNY, Carl von. Zeitschift für geschichtliche Rechtswissenschaft. Berlin: Nicolaifchen Buchhandlung, 1815. Vol. I, p. 3ss. um povo. É uma formação "orgânica" que não pode nem deve ser plasmada arbitrariamente pelos indivíduos ou pelas distintas gerações; é, ao contrário, uma formação que se lhes contrapõe, como algo superior ao arbítrio do indivíduo, das gerações e da sabedoria humana. Desta afirmação, a referida Escola derivou certas consequências, em parte extremamente práticas. Concluiu que o desejo de reformar as condições sociais e políticas, que a Revolução Francesa suscitou em toda a Europa, significava, na realidade, uma negação da natureza do direito, do Estado e da sociedade, bem como de sua "origem orgânica", e que a "sabedoria inconsciente", que se manifestava nas instituições políticas que se haviam formado de maneira orgânica, superava, em muito, a insolente sabedoria humana. Logo, deduziu também que os pioneiros das ideias reformistas deveriam ter confiado menos em sua própria inteligência e energia, e deixado a transformação da sociedade para o "processo histórico de desenvolvimento"; abraçou, enfim, outros princípios igualmente conservadores, muito úteis aos interesses dominantes.

A ideia de uma orientação conservadora análoga, no campo da economia, era bastante óbvia, e uma Escola Histórica de economistas que, seguindo o critério da Escola Histórica do Direito, tivesse defendido as instituições econômicas e os interesses existentes contra os exageros reformistas no campo econômico, e, sobretudo, contra o socialismo, teria desempenhado, na Alemanha, uma importante missão, e prevenido, no futuro, alguns contratempos tardios.

Mas nada mais distante dos economistas da Escola Histórica, na Alemanha, do que uma orientação conservadora na economia; sua orientação histórica era, a esse respeito, algo bastante superficial, desprovida de qualquer fundamento sério. $\mathrm{Na}$ verdade, seus representantes mantiveram, até pouco tempo atrás, relações práticas quase exclusivamente com os políticos liberais progressistas, no campo da economia; e, mais recentemente, uma parte não pequena deles ofereceu-nos, inclusive, o raro espetáculo de uma escola histórica de tendências 
socialistas. Tratou-se de uma curiosidade científica, cujo desenvolvimento posterior foi impedido, mais por acontecimentos externos do que por razões científicas. Em suma, a representação orgânica da economia política segue sendo, para os nossos economistas da Escola Histórica, algo superficial, uma concepção teórica. Não lhes ocorreu, sequer remotamente, tirar dessa visão teórica as consequências práticas, como fizeram os representantes da Escola Histórica do Direito. Nem sequer uma única vez os nossos economistas historicistas tiraram de tal pressuposto as consequências práticas realmente justificadas para a economia.

As conclusões que os nossos economistas historicistas deduziram da referida concepção da natureza da economia (entendida como um todo orgânico unitário) referiam-se, quase exclusivamente, a questões de técnica científica, e caracterizavam claramente o raio de visão desta escola.

Considerar a economia política como um todo particular, diferente dos fenômenos singulares da economia humana, significava considerar seus fenômenos como objeto exclusivo do tratamento científico na economia política teórica, ficando excluídos da economia humana, portanto, os fenômenos singulares. Assim, nem a natureza geral dos fenômenos econômicos, nem a sua conexão geral deviam ser objeto da investigação no campo da economia teórica. A partir deste ponto de vista, apenas o estudo dos fenômenos econômico-sociais podia ser considerado tarefa da economia política, ao passo que o estudo da natureza e da conexão geral dos fenômenos individuais da economia humana foi banido do âmbito de nossa ciência, pois implica em uma confusão entre as maneiras de considerar a economia privada e a economia política, e até mesmo a aspiração de reduzir os fenômenos econômico-sociais aos fenômenos individuais da economia humana foi chamada de "atomismo".

É claro que se trata deuma opinião errônea, cujas motivações imediatas devem-se buscar na confusão entre o ponto de vista histórico e a investigação teórica ${ }^{15}$ e, em última instância, no desconhecimento da verdadeira natureza da "economia política" e de suas relações com as economias individuais que a integram.

O povo como tal não é um sujeito em larga escala - que tem necessidades, trabalha, pratica uma atividade econômica e consume; e o que se denomina Economia Política (Volkswirthschaft) não é a economia de um povo, no sentido próprio do termo. A economia política não é um fenômeno análogo às economias individuais dentro da coletividade, àsquais pertencetambém a economia financeira. Não é uma economia individual em larga escala e, menos ainda, algo que se contrapõe às economias individuais ou existe juntamente com elas. Em sua forma fenomênica mais geral, é, propriamente, uma multiplicidade de economias individuais, como precisamos em outro lugar ${ }^{16}$.

Os fenômenos da economia política não são, em absoluto, expressões imediatas da vida de um povo enquanto tal, isto é, resultados imediatos e diretos de uma "coletividade que atua economicamente"; são, antes, a resultante

15 Depois do que foi dito no capítulo anterior, não é necessário observar, ainda, que esta opinião corresponde, em grande medida, à orientação especificamente histórica que os economistas alemães da Escola Histórica preferiram aplicar também na economia teórica. A história compreende os fenômenos humanos sempre do ponto de vista da observação coletiva, porque só assim pode satisfazer sua função específica de forma universal, e não reduzindo os fenômenos sociais à ação dos indivíduos. Daí que os economistas alemães da Escola Histórica, de formação predominantemente histórica, pensaram que se podia aplicar seu modo de pensar ao campo da investigação teórica. A opinião mencionada apresenta-se-nos como uma forma particular do erro metodológico geral da Escola Histórica, a saber, a aplicação mecânica dos pontos de vista especificamente históricos à investigação teórica, erro a que já nos referimos repetidas vezes e cuja crítica é um dos principais objetivos deste trabalho.

${ }^{16}$ Ver: "Apêndice I: A Natureza da Economia Nacional". [N. do T.: MENGER, Carl. Appendix I: The Nature of National Economy. In: Investigations into the Method of Social Sciences with Special Reference to Economics. Ed. Louis Schneider; Intr. Lawrence H. White; Trad. Francis J. Nock. New York: New York University Press, 1985. p. 193-96]. 
de todas as inumeráveis atividades econômicas dos indivíduos e, por isso, não podem ser entendidos a partir deste ponto de vista fictício. Os fenômenos da economia política só podem ser entendidos teoricamente se interpretados como fruto das atividades econômicas dos indivíduos.

Scire est per causas scire ${ }^{17}$. Logo, aquele que deseja compreender teoricamente os fenômenos da economia política - esses fenômenos humanos complexos que costumamos designar por tal expressão deve remontar a seus verdadeiros elementos, ou seja, às economias individuais da nação, e investigar as leis por meio das quais tais fenômenos formam-se a partir das referidas economias. Mas aquele que segue o caminho contrário desconhece a natureza da economia política e caminha sobre um fundamento fictício, e, ao mesmo tempo, ignora a tarefa mais importante da orientação exata da investigação teórica, que consiste em reduzir os fenômenos complexos a seus elementos mais simples.

O coletivismo unilateral, na consideração dos fenômenos econômicos, é simplesmente inadequado para a orientação exata da investigação teórica e, portanto, não tem fundamento a imputação de "atomismo", no sentido que acima demos a esse termo, lançada contra a economia exata. Essa reprovação atinge tanto a economia quanto as outras ciências exatas, na medida em que são ciências exatas.

Mas, mesmo relativamente à orientação realista, no campo econômico, tal imputação não se justifica. Toda teoria, de qualquer tipo que seja, e independentemente do grau de rigor do conhecimento a que aspira, tem, em primeiro lugar, a missão de permitir-nos conhecer os fenômenos concretos do mundo real, tanto quanto são exemplificações de uma certa regularidade na sucessão dos fenômenos, isto é, geneticamente. Por conseguinte, toda

\footnotetext{
${ }^{17}$ Literalmente, esta expressão latina significa: "Saber é saber pelas causas". Ou seja, o verdadeiro saber é aquele que revela as causas do que se deseja conhecer. [N. do T.]
}

teoria esforça-se, sobretudo, para nos explicar os fenômenos complexos de seu próprio âmbito científico, como resultado da ação conjunta dos fatores que os originaram. Este elemento genético é inseparável do conceito de ciência teórica.

A orientação realista, na economia, aspira sempre, pois, a estabelecer as leis empíricas dos fenômenos complexos da atividade econômica. Todavia, não pode, de modo nenhum, deixar de lado a tarefa de reduzilos a seus fatores originários, aos fenômenos singulares da economia humana, na medida e forma compatíveis com a ideia de investigação realista. Logo, é verdadeiramente absurdo criticar um teórico por ele preocupar-se com o fator genético na teoria.

Finalmente, quanto à acusação de que, na orientação genética, na teoria de nossa ciência, "economia política" e "economia privada" são confundidas, ela se justificaria se a orientação teórica genética não levasse em conta a complexidade dos fenômenos econômicos que integram a economia política, ou se pretendesse deixar de lado os fenômenos singulares da economia humana como elementos da mesma. Enquanto, porém, a orientação genética continuar a tentar resolver esse problema, não se poderá falar, com propriedade, de uma confusão entre economia privada e economia política.

Além do mais, tudo isso é tão evidente que alguns autores, em sua apresentação sistemática da teoria econômica, não conseguiram evitar, de todo, a redução dos fenômenos mais complexos da economia política aos fenômenos singulares da economia humana. Entre eles estão, inclusive, autores que, em suas discussões metodológicas, expressam a perspectiva antiatomística, a qual ignora a natureza das ciências teóricas. Com isto surge, também, aquela contradição entre teoria e prática, tão característica dos economistas alemães da Escola Histórica. cos 